\title{
Educação e Estratégias dos Trabalhadores de Chão-de-Fábrica para Ocupação de Cargos de Chefia
}

Resumo: O presente artigo é resultado de um estudo das estratégias empreendidas por trabalhadores de chão-de-fábrica para ocupação de cargos de chefia. Foram pesquisados seis trabalhadores através da reconstrução de suas trajetórias e estratégias. Enquanto as estratégias da família estão centradas na educação pelo trabalho no lar e em pequenas oficinas e na troca de informações entre conhecidos, as dos trabalhadores de fábrica baseiam-se na conformidade, detenção de "macetes" e culpabilização do subordinado. A conclusão do estudo demonstra que as estratégias não são resultado de uma racionalidade, mas de um esforço que o trabalhador coloca em prática para conseguir emprego e mantê-lo face à sua

\section{Luiz Carlos Brant}

Psicólogo (UFMG) Mestre em Epidemiologia pela UFMG. Doutorando em Saúde e Trabalho pela

Escola Nacional de Saúde Pública/FIOCRUZ - Rio de Janeiro.

\section{Carlos}

Pesquisador do Centro de Estudos da Saúde do Trabalhador e Ecologia Humana. Escola Nacional de saúde Pública, Fundação Oswaldo Cruz, Rio de Janeiro.

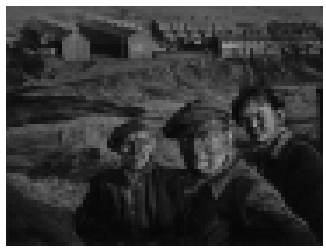
precária profissionalização formal e pequeno capital sócio-cultural relacionado à sua origem de classe. Palavras-Chave: Psicossociologia do trabalho, educação operária, chão-de-fábrica, gerenciamento.

Abstract:The present article is the result of a study on the strategies undertaken by the factory's groundfloor workers to achieve chief positions. Six cases of workers were investigated through the reconstruction of their occupational trajectories and estrategies. As a conclusion, the strategies are not the result of a rationality but of an effort made by the factory's ground-floor worker to get a job and to maintain it due to the precarious formal professionalization and the small social and cultural wealth related to his class origin. Key Words: Psychosociology of work, labor education, factory's ground-floor, management.

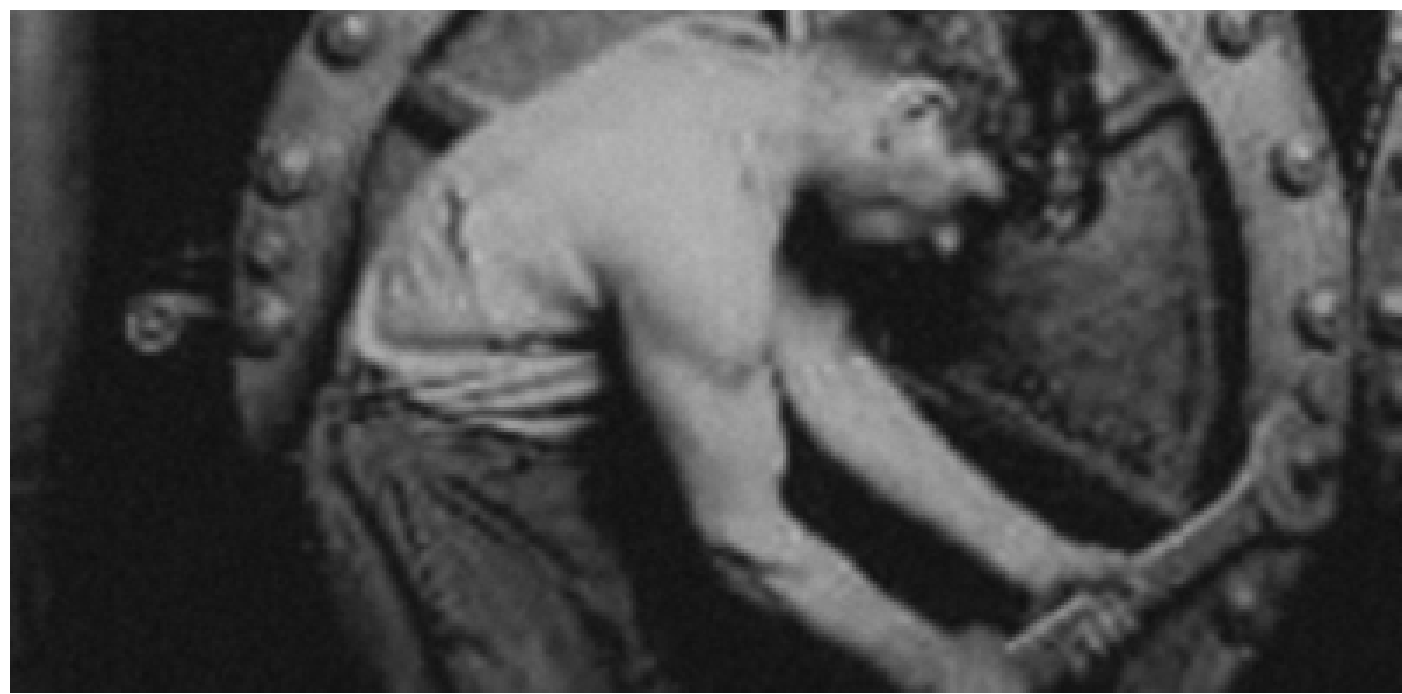

Partindo de um recorte teórico da tese de doutoramento de um dos autores e do estudo piloto de entrevistas com trabalhadores de chão-de-fábrica, utilizando como instrumento a reconstrução de trajetórias e estratégias ocupacionais, os autores procuram identificar as estratégias empreendidas pelos operários para se tornarem e se manterem chefes, sub-encarregados, encarregados ou supervisores de área. Os trabalhadores que assumem esses cargos tornam-se reguladores do processo produtivo (Marx, 1974). O conjunto desses trabalhadores de chão-de-fábrica pode ser definido como a base da pirâmide hierárquica e de mando. Para Marx (1989), as diversas capacidades de trabalho cooperam e formam a máquina produtiva total. Há uma participação muito diferenciada no processo 
imediato de formação dos produtos; "um trabalha mais com as mãos, outro mais com a cabeça, este como diretor (manager), engenheiro (engineer), técnico, supervisor (over-looker) e aquele outro operário manual ou até como simples servente".

A gestão da força de trabalho pode ser definida como uma prática social historicamente constituída de funções 1) disciplinar-econômica, que visa a maximizar a produtividade do trabalhador através de práticas que capturam o sujeito em sua totalidade, submetendo-o a dispositivos como: recrutamento, seleção, treinamento e programas de acompanhamento de pessoal; 2) disciplinar-política, que objetiva destituir o trabalhador, como sujeito de desejo, de sua capacidade de resistência, sob as formas de organização coletiva e contestação. $O$ cumprimento desse processo se faz através de reiteradas tentativas da equipe gerencial de operar um desenraizamento do trabalhador de sua terra originária para melhor enraizá-lo no solo da empresa, apagar suas referências originais e substituí-las por outras mais de acordo com os interesses do capital, procurando sempre transformá-lo em um recurso humano (Brant, 2001).

Para Braverman (1980), o capitalista, por meio da gerência (management), empenha-se em assumir o controle da situação que envolve o trabalho, confiscando também toda a vida do trabalhador, em última instância. Conseqüentemente, o trabalhador perde não apenas o controle sobre o ato produtivo, mas, sobretudo, é desapropriado da autonomia de estabelecer seu próprio ritmo de trabalho, ficando, assim, privado da sua condição de sujeito, de sua prática (desconstrução subjetiva da força de trabalho) para assujeitar-se à cadência imposta por um outro trabalhador considerado superior. Assim, torna-se necessário compreender, de forma sistemática, como se realiza essa complexa constituição do gerenciamento no chão-de-fábrica e que processos culturais e subjetivos estão nela envolvidos.

No que diz respeito ao termo "cargo", Weber (1966) afirma que a pessoa que representa tipicamente a autoridade ocupa um "cargo", ou seja: "na atividade específica de seu status, que inclui a atividade de mando, está subordinada a uma ordem impessoal para a qual se orientam suas ações. Isso é verdadeiro não apenas para os que exercem a autoridade legal inscrita no conceito usual de "funcionários", mas, por exemplo, para o presidente eleito de um Estado".

O que faz com que alguns trabalhadores ocupem cargo de comando e outros não? Como os "escolhidos" para chefiar surgem e são definidos? Qual o perfil social e subjetivo desses trabalhadores "escalados" no chão de fábrica? Este estudo parte das seguintes hipóteses: 1) que a ocupação de cargos gerenciais é fruto de estratégias; 2) que essas estratégias utilizadas pelos trabalhadores operam a desconstrução subjetiva da força de trabalho e subsunção, mas também evidenciam processos de resistência e reprodução social.

Partindo do princípio de que o exercício gerencial, no modo de produção capitalista, é pura manifestação social e política de um grupo hegemônico, que não se restringe a uma certa cultura organizacional, mas a um conjunto de relações estabelecidas no interior da sociedade, pretende-se: 1) estudar, a partir da ótica dos trabalhadores do chão-de-fábrica, as estruturas que lhes possibilitaram a inserção e a manutenção na função de controle político, técnico e subjetivo sobre outros trabalhadores, realizando, assim, uma das várias estratégias perversas do capital; 2) compreender os mecanismos que permitem a esses trabalhadores acreditar que possuem poder sobre outros trabalhadores, "fechar os olhos para grandes injustiças que sofrem os colegas" (Minayo-Gomez e Machado, 2000) e "esquecer" sua própria condição de trabalhador. Acredita-se que as estratégias empreendidas por esses trabalhadores expressam diferentes processos de resistência, produção cultural, reprodução cultural e social.

Este trabalho procura evidenciar as estratégias dos trabalhadores do chão-de-fábrica para ingresso e manutenção no cargo gerencial em uma empresa prestadora de serviços do setor ferroviário. Reservados os limites de exploração de um artigo, procura-se aqui dar visibilidade a alguns aspectos da cultura "contra-escolar" relacionados ao processo de educação de trabalhadores originários das camadas populares que priorizam o emprego.

\section{A Pesquisa}

\section{Caracterização da população}

Investigou-se um grupo de seis supervisores de área pertencentes a uma empresa de pequeno porte, prestadora de serviços de manutenção do setor ferroviário, na região metropolitana de Belo Horizonte. Os investigados representaram a totalidade dos gestores de chão-de-fábrica, ou seja, constituíam o primeiro nível gerencial de uma unidade operacional, chefiando diretamente grupos de trabalhadores braçais: soldadores, mecânicos, eletricistas e operadores de máquinas ferroviárias. Possuíam, em média, 18 anos de trabalho na profissão e estavam há 11 anos, em média, no exercício do cargo gerencial, sendo que o primeiro cargo de comando ocorreu, em média, 7 anos após o ingresso na profissão. Sua média de idade era de 37 anos. Entre os entrevistados, apenas um era portador de curso superior na área de Educação, dois tinham segundo grau completo e os outros, primeiro grau. Com exceção do supervisor, portador de curso superior, todos os entrevistados tinham se desligado, através do "Pedido de Demissão Voluntária", de uma empresa pública do setor ferroviário que foi privatizada, antes de ingressarem na atual empresa. 


\section{Técnica de investigação}

Utilizando a Reconstrução das Trajetórias e Estratégias Ocupacionais (RTEO), foram investigadas as estratégias empreendidas pelos supervisores para o ingresso e manutenção no cargo de chefia. A RTEO, como técnica de reconstrução da história de trabalho, se fez através do ato de rememorar, colocar em palavras: imagens, idéias e lembranças do caminho percorrido para ocupar um cargo de comando e o significado atribuído a esse percurso. Em termos operacionais, a RTEO realizou-se por meio de entrevistas abertas, semi-estruturadas, individuais, visando à apreensão dessas estratégias a partir da ótica dos próprios trabalhadores. Essa técnica parte do princípio de que, ao se expressar em uma situação de entrevista, o

\section{A entrevista aberta constitui material privilegiado da análise da enunciação, no sentido de que se trata de um discurso dinâmico onde \\ espontaneidade e constrangimento são simultâneos, onde o trabalho de elaboração se \\ configura, ao mesmo tempo, como emergência do inconsciente e construção do discurso.}

Minayo

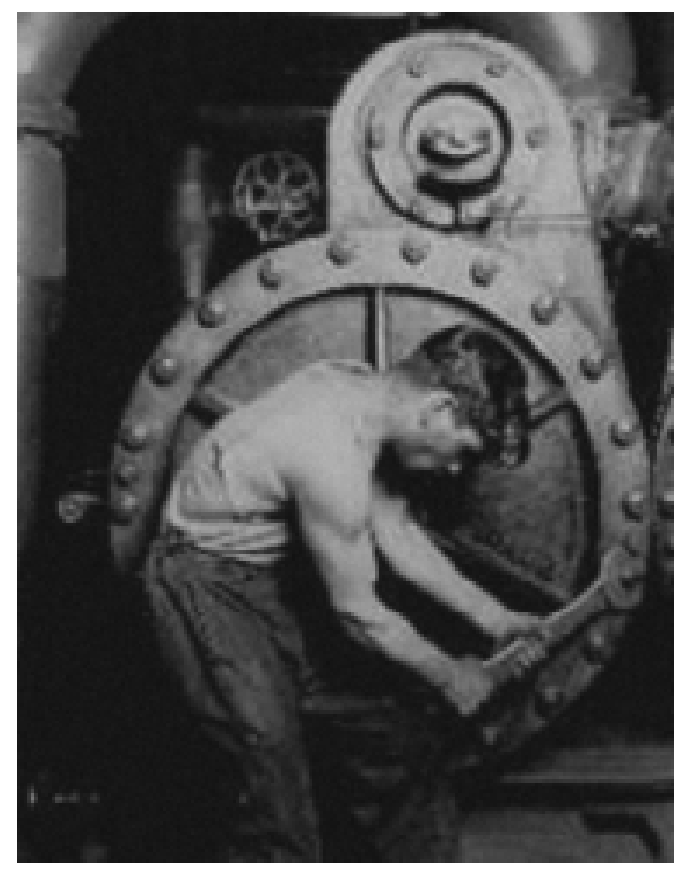

locutor projeta seus conflitos básicos através de palavras, silêncios, risos, chistes, repetições, lacunas, sons, em suma, significantes, na sua maioria, inconscientes. Minayo (1996) afirma que a entrevista aberta constitui material privilegiado da análise da enunciação, no sentido de que se trata de um discurso dinâmico onde espontaneidade e constrangimento são simultâneos, onde o trabalho de elaboração se configura, ao mesmo tempo, como emergência do inconsciente e construção do discurso.

A Reconstrução de Trajetórias e Estratégias Ocupacionais levou em consideração: 1) o comportamento narrativo como um ato mnemônico de notável alcance, uma vez que permite comunicar ao outro informações distantes dos acontecimentos ou dos objetos que constituem sua motivação (Bosi, 1994); 2) o discurso do trabalhador determinado por condições materiais de produção, por estruturas semânticas (significantes) e por estruturas sociológicas (significados). Em síntese, a RTEO cumpriu os seguintes objetivos na pesquisa: 1) sistematizar, espacial e temporalmente, situações relacionadas ao ingresso e manutenção no cargo de comando; 2) descrever as estratégias utilizadas - a descrição é reveladora do modelo institucional do processo de dominação e de resistências implícito na empresa; 3) verificar a implicação face ao cargo - a maneira como o trabalhador organiza a sua prática, o que reflete suas estratégias e o grau de compromisso com o trabalho.

Neste estudo, estratégia foi entendida na perspectiva bourdiniana, ou seja, como um conjunto de práticas e atitudes ideológicas ou morais que, consciente ou inconscientemente, cada grupo social põe em prática com uma determinada finalidade (nesse caso, admissão e permanência num cargo de comando). Tais práticas pertencem ao ethos de uma classe e podem ser definidas como o resultado do processo pelo qual diferentes grupos sociais interiorizam sua situação objetiva. Essas práticas são "inteligíveis e coerentes sem serem fruto de uma intenção inteligente e de uma decisão deliberada; ajustadas ao futuro, sem serem o produto de um projeto ou de um plano" (Bourdieu, 1989).

\section{Método de análise dos dados}

O texto obtido através da RTEO foi trabalhado pelo método da análise de conteúdo, tomando por base teórica: Bardin (1977), Triviños (1987) e Minayo (1993). Bardin (1977) afirma que a análise do conteúdo constitui "um conjunto de técnicas de análise das comunicações, visando, por procedimentos sistemáticos e objetivos de descrição do conteúdo das mensagens, a obter indicadores que permitam a inferência de conhecimentos relativos às condições de produção/recepção das mensagens". Explicita como características metodológicas da análise de conteúdo a objetividade e a sistematização. Sugere regras para se trabalhar adequadamente essas características, de forma a facilitar a construção das "categorias" de fragmentação do enunciado, validando assim, a sua análise. E define, ainda, categorias como: "rubricas ou classes as quais reúnem um grupo de elementos sob um título genérico, agrupamento esse efetuado em razão dos caracteres comuns desses elementos". Com o método das categorias, é possível trabalhar o texto como um todo, através de técnicas de classificação e recenseamento em que se captura a freqüência dos elementos de significação da mensagem, considerando a sua presença ou ausência. Esse método visa, através da adoção de certos critérios, a estabelecer uma ordem ao se defrontar com uma desordem aparente.

Triviños (1987) orienta que o investigador, ao adotar a análise de conteúdo como método, deverá trabalhar, através de seu suporte teórico e de 
informações histórico-culturais, os pontos de vista do entrevistado, advertindo ser importante o respeito às perspectivas individuais ou grupais desses pontos de vista. $\mathrm{O}$ autor chama a atenção para o trabalho de interação dos materiais, durante o qual não é possível que o pesquisador detenha sua atenção exclusivamente no conteúdo manifesto do texto. Ele deve aprofundar sua análise tratando de desvendar o conteúdo latente que eles possuem.

Minayo (1996) situa que a análise de conteúdo visa a alcançar, através de uma vigilância crítica em um nível mais aprofundado, os significados manifestos dos enunciados analisados, superando o senso comum e o subjetivismo. Dessa forma, os seus procedimentos técnicos, ao se analisar um enunciado, devem integrar as estruturas semânticas ou lingüísticas, entendidas como significantes, às estruturas sociológicas ou psicológicas a que correspondem os significados caracterizados pelo contexto cultural, psicossocial e a compreensão de todo o "processo de produção da mensagem".

\section{Resultados e Discussão}

\section{As estratégias das famílias}

Diferentemente das classes mais favorecidas, em que a preocupação primeira das famílias é com o projeto escolar dos filhos, (projeto voltado para a obtenção de um lugar privilegiado no sistema escolar por meio do qual a entrada no mercado de trabalho se faz como uma "conseqüência natural"), o projeto das famílias das camadas populares é, prioritariamente, para o emprego, ficando a escola para um segundo plano.

Para as classes mais favorecidas, ocupar um cargo gerencial numa empresa de grande porte geralmente assume significação de sucesso profissional reconhecido e valorizado socialmente, concluindo assim o projeto escolar da família. Nessas classes, impera o ethos da ascensão social - ocupar uma colocação de destaque -, primeiramente, na escola e depois no mundo do trabalho. A fala popular é sábia quando associa obtenção de emprego com colocação o que implica afirmar que o "herdeiro" é colocado em um determinado cargo, isto é, uma ação que ele sofre de algo externo, quer seja da família, da posição de classe ou do mercado de trabalho. A colocação num cargo gerencial reproduz um determinado imperativo social: "que sejam favorecidos os mais favorecidos e desfavorecidos os mais desfavorecidos", na contundente expressão de Bourdieu (1989).

\section{A educação pelo Trabalho}

Nas classes populares, a frágil busca de um estabelecimento escolar para os filhos, tarefa quase exclusiva da mãe, segundo Portes (1993), parece não ser suficiente para permitir uma "longevidade" no sistema escolar. As dificuldades em auxiliar os filhos nos conteúdos das tarefas escolares, em geral, são "compensadas" por intervenções na esfera da moral, através de aconselhamento e treinamento em trabalhos domésticos, tanto no próprio lar, quanto em casas de vizinhos. Os trabalhadores investigados, quando se referem às mães, indicam que essas estavam sempre preocupadas com que os filhos não "saíssem do eixo" e com as relações mantidas com os colegas que não querem "nada com a dureza". Além da violência física, um componente presente na educação dos filhos das camadas populares, de acordo com Portes (1993), as medidas corretivas dessas famílias sinalizam o trabalho como um mundo possível para aqueles que "não têm cabeça para os estudos". Diante das reprovações nas primeiras séries escolares, alguns entrevistados recordam que recebiam atividades domésticas como punição: lavar banheiro, arrumar cozinha, catar feijão e varrer quintal. Na medida em que os trabalhos domésticos são utilizados como instrumento corretivo e transmissão de certos hábitos de trabalho, eles se tornam penosos e motivo de vergonha para os filhos. Detentor de uma significação social de trabalho desqualificado, feminino e objeto de castigo, esse tipo de educação pelo trabalho colabora para a formação da subjetividade do futuro trabalhador que se manifestará na subserviência aos "superiores", na resignação diante de trabalhos penosos e na crença de que a realização de trabalhos não valorizados socialmente se deve a um fracasso pessoal.

Enquanto a escola formal tem pouca serventia na preparação da força de trabalho, os processos informais de educação (casa, vizinhança, meios de comunicação e a experiência de trabalhos domésticos) constituem fortes elementos que entram, continuamente, na reprodução da situação de classe, na constituição da subjetividade do trabalhador e na forma pela qual esse empreenderá sua força de trabalho no mercado.

\section{As Oficinas de Conhecidos: pequeno Capital Social}

A rede de relações, influências e informações pertencentes ao pequeno capital social e cultural dessas famílias parece indicar o mundo do trabalho como uma solução, a curto prazo, para a sobrevivência material e cultural da prole. Tal situação distancia os filhos das classes populares da escola que, por sua organização e funcionamento oficiais, não consegue responder às necessidades materiais e simbólicas imediatas das famílias trabalhadoras. Os filhos da classe operária vivem no mundo do "presente imediato" e no "aqui e agora", onde pouca consideração ou preocupação é dirigida ao futuro (Willis, 1991). Foi possível observar que os

\section{Diferentemente das classes mais favorecidas, em que a preocupação primeira das famílias é com o projeto escolar dos filhos, (projeto voltado para a obtenção de um lugar privilegiado no sistema escolar por meio do qual a entrada no mercado de trabalho se faz como uma "conseqüência natural"), o projeto das famílias das camadas populares é, prioritariamente, para o emprego, ficando a escola para um segundo plano.}


entrevistados, desde muito jovens, se autorepresentam como detentores de uma "capacidade limitada", de forma que idéias a respeito de uma carreira escolar normal são descartadas.

Constatou-se que a entrada no mundo do trabalho ocorreu quando criança, com idades que vão dos 8 anos (vendedores de picolé, frutas, doces e engraxates) aos 13 como aprendizes em oficinas mecânicas, gráficas, marcenarias e serralharias onde os pais, parentes ou vizinhos trabalham. Observou-se que esses trabalhadores, desde crianças e adolescentes, encontravam um "gosto maior" no trabalho quando comparado com as atividades escolares. No entanto, não se dão conta de que tal "gosto" relaciona-se com uma estratégia de classe que demanda trabalho infantil e que reforça o "ganho" imediato na luta pela sobrevivência. Para Portes (1993), nas famílias das classes populares, é possível identificar um comportamento que assinala aos filhos, desde a mais tenra idade, um alerta para um futuro de trabalho semelhante ao do pai, caso fracasse na escola. A instauração da possibilidade do fracasso escolar cumpre a finalidade de estimular a produtividade, incentivando a busca de uma "carreira de sucesso" que seria a de assumir um cargo de comando no interior da fábrica.

Entre os entrevistados, o trabalho em oficinas, na adolescência, ponto de partida para a grande fábrica, possibilitou a familiarização com um instrumental complexo e o desenvolvimento de hábitos de trabalho bem definidos. Aprenderam que o trabalho deve ser produtivo, que sua concepção ocorre em outro lugar, que o produto tem um destino desconhecido e que poucos mandam e muitos devem obedecer. "Quem pode manda, quem tem juízo obedece", na expressão de um dos supervisores. Descobriram, também, que o pai ou a mãe e mesmo o avô já haviam realizado o percurso da oficina, como uma espécie de tradição.

Enquanto nas classes privilegiadas a escola cumpre a função de formação de profissionais para atuar na concepção do processo de trabalho, as oficinas, nas classes populares, têm como objetivo uma formação técnica e social que possibilite uma orientação na vida ocupacional e a formação de uma reserva onde a indústria recrutará operários semiqualificados. Essa formação é prática para viabilizar a transição entre um universo escolar "sem sucesso" e a dimensão da fábrica, onde a divisão social exige a construção de estratégias para lidar com as relações de poder.

\section{A Rede de Informações Sobre o Emprego}

A informação recebida sobre o concurso para ocupação de cargos na empresa pública a que pertenciam é reveladora de uma das estratégias das classes populares em relação à obtenção de empregos.
A informação oral, obtida através de parentes, vizinhos ou amigos trabalhadores daquela empresa foi a mais citada, seguida da informação de parentes ou conhecidos que trabalham como empregadas domésticas, faxineiras ou cozinheiras em casas da classe média. Todos se recordavam da informação de que se tratava de um "empregão" para a vida toda, e que havia a possibilidade de se fazer carreira.

Foi perguntado aos entrevistados o que seria um ótimo emprego. E as respostas privilegiaram: a estabilidade (de modo que se possa trabalhar até se aposentar) e os direitos trabalhistas mais elementares, entre eles, ter a carteira assinada (ser fichado) e gozar de assistência médica, inclusive para toda a família. Compreende-se, assim, que a luta do trabalhador se dá mais por vínculo empregatício do que pela realização profissional plena. Isso assinala, de forma real, a existência de uma estratégia de busca de emprego em empresas públicas, acreditando ser este permanente e seguro. Trabalhar em uma empresa pública é visto, pelo conjunto dos entrevistados, como necessário e importante para a realização de suas aspirações futuras, mesmo diante da percepção das pequenas chances de ser aprovado em um concurso público, dadas as limitações de sua escolaridade e condição de classe.

Existem processos culturais, no interior das famílias operárias, que realizam a preparação das forças de trabalho individuais e que entram na constituição subjetiva do trabalhador. Esses processos, "encarnados" em sujeitos reais e concretos, atravessam as relações de trabalho sob a forma de submissão e de resistência. O estudo do processo de preparação para o trabalho e a "escolha" do emprego, gestados pela própria família (sem muita ajuda do sistema escolar), mesmo marcando, exemplarmente, as estratégias dos trabalhadores de chão-de-fábrica, não se mostram suficientes. Faz-se necessária uma investigação do sujeito e de sua articulação com a estrutura social.

\section{As estratégias dos trabalhadores}

Desde o primeiro dia de trabalho, passando pela inserção cultural no mundo da "fábrica" até a nomeação para um cargo gerencial, existe uma longa travessia que implica a necessidade de empreender estratégias diversas para superar múltiplas e variadas dificuldades. A inserção cultural no chão-de-fábrica é, em parte, facilitada pela cultura geral de classe, caracterizada pela origem dos entrevistados (as camadas populares) e pelo fato de já terem trabalhado em uma empresa do setor produtivo. Mas esses elementos não são suficientes para uma plena ambientação, como se poderia acreditar a princípio. O trabalhador vai se deparar com uma dimensão específica da empresa pesquisada: um chão-defábrica de serviços terceirizados. Essa especificidade vai exigir do trabalhador a construção de novas 
estratégias, além da adaptação daquelas já aprendidas em outras empresas, capacidade esta que se tornará um importante elemento na escalada daqueles que ocuparão postos de comando.

\section{A Conformidade: mostrar o Melhor}

Manter uma "boa relação com a chefia" e, ao mesmo tempo, com os colegas é uma das estratégias que têm por objetivo tentar eliminar a separação "nós e eles", o que transforma o futuro supervisor de área em "um dos nossos", tanto para a equipe gerencial quanto para os outros trabalhadores da oficina. Analisando a relação desses trabalhadores com a chefia e os colegas, pode-se afirmar, com Willis (1991) e Portes (1993), que se trata de trabalhadores conformados, que acatam as determinações dos "superiores", sem nenhum questionamento quanto às exigências e cobranças e fazem semblante de concordar sempre com as ordens estabelecidas. Tornaram-se "exemplos" para os outros, pelo desempenho profissional, pela sua dedicação e constante prontidão para atender demandas de trabalho, a qualquer hora, mesmo nos finais de semana e feriados.

\section{"Macetes": um Capital da Força de Trabalho}

A organização prescrita do trabalho não oferece todas as informações necessárias para a execução de uma tarefa. O conhecimento operacional não é propriedade daqueles que trabalham na concepção, mas pertence a poucos no chão-de-fábrica. Esses são detentores de um saber não-oficial que é transmitido, ritualistica e estrategicamente, pela tradição oral, de trabalhador para trabalhador (apenas àqueles que fazem parte dos "nossos"), configurando um espaço de resistência entre força de trabalho e capital. Esse saber marca o papel das diversas profissões no chão-de-fábrica, estabelece vínculos de respeito e confiança entre os mais jovens e os "macacos velhos", instaura "a verdadeira escola", conforme expressões de um entrevistado. O "macete", como é chamado esse saber, possui um caráter vital, pois é graças a ele que os trabalhadores conseguem construir, controlar ou dominar um processo de trabalho compondo, técnica e politicamente, o coletivo no chão-de-fábrica.

Descobrir "macetes" significa ser detentor de modos operacionais eficazes e de uma alta governabilidade porque se domina um considerável número de variáveis capazes de executar operações vitais. Existe um movimento de busca e apreensão de "macetes" desde os primeiros anos de admissão ao trabalho, condição que coloca esses trabalhadores sempre em evidência entre colegas e administradores, constituindo assim uma das estratégias para ocupar cargo de comando. A qualificação dos trabalhadores, através dos "macetes", pertence ao contexto da "cultura contra-escolar" do chão-de-fábrica, conforme expressão de Willis (1991). Ela torna presente uma possível rejeição à obediência que a escola procura obter dos garotos de classe operária. Quando esses garotos se transformam em trabalhadores, trazem para o chão-de-fábrica um ceticismo profundamente arraigado quanto ao valor das qualificações formais que são sempre a longo prazo e que envolvem grandes sacrifícios. A formação através de "macetes" produz uma gratificação simbólica imediata de acordo com o estilo de vida do trabalhador, em qualquer tempo, além de possibilitar condições para solucionar problemas que a organização do trabalho prescrita não é capaz de fazer. Estabelecendo uma analogia entre a organização do trabalho prescrita e a formação escolar, esse trabalhador constata que ela não oferece soluções imediatas; ele aprende o valor que o "macete" ocupa na organização do trabalho real, à medida que possibilita responder, de acordo com os interesses do coletivo dos trabalhadores, a demandas técnicas diversas.

Uma vez supervisor de área, o trabalhador se torna gerente de um furo entre a organização do trabalho prescrito e a organização do trabalho real, e vai fazer do "macete" um dos elementos possibilitadores da sua administração, mantendo sob seu controle tanto "os superiores" quanto os outros trabalhadores. Assim procedendo, o supervisor conquista um destaque que deverá ser sustentado pelos colegas e reconhecido pelos "superiores". É na perspectiva do "macete" como capital da força de trabalho que "nunca se passa um "macete" de mão beijada" no interior do chão-de-fábrica. A sua transmissão exige um esquema de confiança mútua entre os pares, reconhecimento dos "eleitos" para futuros supervisores e sondagem do "clima organizacional", na perspectiva do trabalhador, para liberar ou travar a produção, o que permite concluir que a produção não é apenas regulada pelos limites do capital, mas também, estrategicamente, pela força de trabalho.

\section{As Estratégias de Manutenção no Cargo Gerencial}

Ao constatar ações operacionais que não se enquadram naquilo que foi prescrito, alguns supervisores utilizam a "culpabilização da vítima" como estratégia para não implicá-lo. Fazem um movimento para que o trabalhador assuma a falha, que se coloque como culpado, que acredite que houve, de sua parte, incompetência ou negligência e que jamais pense em tal falha como uma impossibilidade inerente à situação de trabalho. Com esse movimento, o supervisor encobre uma falha estrutural da organização, reafirmando-a como perfeita e completa e instaura o "conceito de falha humana", conforme terminologia de Dejours (1997).
É na perspectiva do "macete"como capital da força de trabalho que "nunca se passa um "macete" de mão beijada" no interior do chão-de-fábrica. 
Conclui-se que o gestor do chão-de-fábrica está assujeitado a um outro que o coloca, designa, nomeia ou escala para esse posto, para fazê-lo cumprir aquilo que é prescrito pela organização do trabalho. Esse lugar, com todas as relações que ele implica, é uma mesclagem de submissão e resistência, de prazer e dor. Entre os entrevistados, foi possível constatar um conflito entre a esperança de criar, de transformar ou de imprimir algo pessoal ao trabalho e a obediência àquilo que é prescrito pela organização do trabalho. É desse lugar de sujeito dividido entre produção e reprodução que o supervisor é capturado. Em uma perspectiva psicanalítica, pode-se afirmar que não é a imagem de completude ou de perfeição da organização que seduz e prende o supervisor ao cargo mas, sobretudo, a existência de um furo nessa imagem. Tal furo provoca um misto de atração e horror, de familiaridade e estranheza, de submissão e desafio no supervisor, aprisionando-o numa dada dimensão humana que tem no mito de Prometeu o seu paradigma. E, como em "Prometeu Acorrentado", esse trabalhador-chefe estará para sempre condenado ao trabalho ordálico, tendo a sua saúde comprometida pelo dilaceramento que um "abutre" produz em seu corpo.

É para tamponar um furo entre concepção e execução, impossível de ser preenchido, que o supervisor é escalado. Enquanto gestor de um furo que não pode se apresentar como tal, pois tornaria a relação do homem com o trabalho insustentável, esse trabalhador desloca a falha da estrutura organizacional para si mesmo, torna-se sujeito cindido e procura sustentar o trabalho a partir desse lugar. Esse deslocamento para si, sob a forma de erro, incompetência ou negligência torna-se o motor que o impulsiona rumo à ilusória completude pregada pela organização prescrita do trabalho que o deixa à mercê da vã esperança de ser reconhecido pelas suas ações.

Na busca do reconhecimento, o gestor do chão-defábrica torna-se adicto de uma estratégia que pode sustentá-lo, obsessivamente, anos a fio. Quando o reconhecimento acontece, o que nem sempre ocorre, é devido a um trabalho executado. A conclusão de um trabalho remete o trabalhador a um sentimento misto de realização e de morte. Trabalho executado é trabalho morto. Diante de uma obra concluída, os supervisores experienciam prazer e angústia, que os remetem a um perpétuo recomeçar, a uma eterna busca de um novo reconhecimento.

\section{Considerações Finais}

Ao mesmo tempo em que as estratégias se mesclam, apresentam elementos diferenciados, principalmente no momento da entrada do sujeito na empresa investigada. Elas não fazem parte de um plano preestabelecido, mas são construídas de acordo com as circunstâncias cotidianas, visando à manutenção do emprego no interior da organização e à sobrevivência, em última instância.
Apesar dos esforços das famílias em construir um projeto de encaminhamento dos filhos ao mercado de trabalho, principalmente diante do insucesso nas primeiras séries escolares, esses não são fruto de uma racionalidade, mas sobretudo de um sobre-esforço desesperado para a sobrevivência. Diante da precariedade das condições materiais de existência dessas famílias, esse projeto é sempre marcado pela imediaticidade, uma vez que seus descendentes, desde muito jovens, são obrigados a participar do orçamento doméstico. Essas famílias apresentam grande dificuldade em suportar um processo seletivo, a longo prazo, como se observa em alguns concursos públicos que exigem todo um ritual burocrático que vai da publicação de um edital, passando pelas provas, até chegar à admissão.

É na perspectiva da luta pela sobrevivência e por um sistema de vida caracterizado por planejamentos a curto prazo que se pode compreender a elevada rotatividade e transferências de trabalho, sem vínculo empregatício, em pequenas oficinas. Pode-se afirmar que as estratégias dos entrevistados são forjadas nesse contexto sócio-econômico e são fruto de um longo processo de aprendizagem que se impõe diante das necessidades e adversidades enfrentadas na luta cotidiana pela obtenção de trabalho mais seguro, que possa oferecer um salário com um mínimo de regularidade. A partir desse quadro social e cultural proporcionado pelos entrevistados, é possível perceber a significação que assume um cargo de comando que é representado, no interior da família, como a uma promessa de uma posição social diferente daquela ocupada pelos pais dos entrevistados.

Assim, ser supervisor implica construção de estratégias individuais e familiares. Uma vez no cargo, esse trabalhador não percebe que foi capturado enquanto sujeito para maximizar a produtividade no chão-de-fábrica e disciplinar seus colegas. O que não significa, necessariamente, "fechar os olhos para as injustiças em relação aos colegas", conforme expressão de Minayo (2000). Fechar os olhos pode não constituir uma estratégia na luta pela manutenção do cargo de gestor no chão-de-fábrica, mas um mecanismo defensivo, expressão da alienação de um trabalhador que perdeu sua condição de sujeito, para figurar-se como "recurso humano" diante de uma primeira cegueira: a das instituições escola e família, que não foram capazes de brindá-lo com um olhar de cuidados básicos. "Só o que me cega, o que me faz infeliz é o brilho do olhar que não sofri", conforme a letra de "Jura Secreta" de Abel Silva e Sueli Costa. Talvez merecessem investigação, não tanto os trabalhadores que fecham os olhos diante das injustiças, conforme sugestão do professor Minayo, mas aqueles que mantêm os olhos abertos, sem ao menos pestanejar, na certeza de poder levar vantagem sobre as dificuldades de um colega. 
Antunes, R. (1995). Adeus ao trabalho? Ensaio sobre as metamorfoses e centralidade do mundo do trabalho. São Paulo: Cortez/Unicamp.

\section{Bosi, E. (1994). Memória e sociedade. São Paulo: Companhia das Letras.}

Bourdieu, P. (1989). A escola conservadora: as desigualdadesfrente à escola e à cultura. Educação em Revista. no 10, 3-15.

Brant, L. (2001). Sujeito e sofrimento entre trabalhadores que ocupam cargo gerencial. Dissertação de Mestrado, Universidade Federal de Minas Gerais, Belo Horizonte.

Braverman, H. (1980). Trabalho e capital monopolista. Rio de Janeiro: Zahar.

Dejours, C. (1997). O fatorhumano. Rio de Janeiro: Fundação Getúlio Vargas.

Marx, K. (1974).Grundrisse: foundations of the Critique of Political Economy. Middleses: Penguin Books.
Marx, K. (1989). Capítulo Vl inédito de O Capital: resultados do processo de produção imediata. São Paulo: Moraes.

Minayo, M. C. (1996). O desafio do conhecimento: pesquisa qualitativa em saúde. 4 ed. São Paulo: Hucitec-ABRASCO.

Minayo-Gomez, C. e Machado, J. (2000). Entrevista com Carlos Minayo sobre questões históricas e atuais do campo de saúde do trabalhador. Rio de Janeiro. Ciência e Saúde Coletiva 5 (2): 419-425.

Portes, E. (1993). Trajetórias e estratégias escolares do universitário das camadas populares. Dissertação de mestrado, Universidade Federal de Minas Gerais, Belo Horizonte.

Weber, M. (1966). Os fundamentos da organização do trabalho burocrático: uma construção do tipo ideal. In: CAMPOS, E. Sociologia da Burocracia. Rio de Janeiro: Zahar, 1966.

Willis, P. (1991). Aprendendo a ser trabalhador: escola, resistência e reprodução social. Porto Alegre: Artes Médicas.
Referências

\section{bibliográficas}

